\title{
Antibody dependent enhancement infection of Enterovirus 71 in vitro and in vivo
}

\author{
Jian-Feng Han ${ }^{\dagger}$, Rui-Yuan Cao ${ }^{\dagger}$, Yong-Qiang Deng, Xue Tian, Tao Jiang, E-De Qin*, Cheng-Feng Qin
}

\begin{abstract}
Background: Human enterovirus 71 (EV71) has emerged as a significant cause of acute encephalitis and deaths in young children. The clinical manifestations caused by EV71 varied from mild hand, foot and mouth disease to severe neurological complications and deaths, but its pathogenesis remains elusive. Antibody dependent enhancement (ADE) infection has been reported in various viruses and has been shown to contribute to disease severity.

Results: In this study, the presence of sub-neutralizing antibody was demonstrated to enhance EV71 infection in THP-1 cells and increase the mortality of EV71 infection in a suckling mouse model. Further, a secondary infection model was established to characterize the correlation between ADE and disease severity, and primary asymptomatic EV71 infection was shown to increase the mortality of the secondary EV71 infection in suckling mice.
\end{abstract}

Conclusions: Together, these in vitro and in vivo experiments strongly supported the hypothesis of ADE infection of EV71. The present findings indicate ADE might contribute to the pathogenesis of severe EV71 infection, and raise practical issues of vaccine development and antibody-based therapy.

\section{Background}

Hand, foot and mouth diseases (HFMD) are common self-limiting illness in infants and young children, characterized by ulcerating vesicles in the mouth and lesions on the hands and feet. Small outbreaks of mild HFMD have occurred periodically throughout the world for a long time. Two closely related viruses, coxsackievirus 16 (CA16) and enterovirus 71 (EV71) have been identified as the most frequent pathogens of HFMD, and other enteroviruses, including CA5 and CA10, can also cause HFMD. While since 1997, large outbreaks of HFMD associated with severe neurological complications and a high case-fatality rate have been reported in Malaysia [1], Taiwan [2], Singapore [3], Japan [4] and other Asian-Pacific areas. In mainland China, large outbreaks of HFMD have been reported since 2008, resulting in millions of cases and hundreds of deaths in children [5]. These severe forms of HFMD have been associated with

\footnotetext{
* Correspondence: qinede@sohu.com; cfqin@hotmail.com † Contributed equally

State Key Laboratory of Pathogen and Biosecurity, Beijing Institute of Microbiology and Epidemiology, Beijing 100071, PR China
}

EV71 infection, which has emerged as an important public health problem.

EV71 is a small, non-enveloped virus with a single positive-stranded RNA genome size of about $7.4 \mathrm{~kb}$ in length. It belongs to the family Picornaviridae, genus Enterovirus together with CA16. Its open reading frame encodes a polyprotein, flanked by 5' and 3' untranslated regions (UTRs). The polyprotein can be further processed into four capsid proteins (VP1, VP2, VP3 and VP4) and seven nonstructural proteins (2A, $2 \mathrm{~B}$ and $2 \mathrm{C}, 3 \mathrm{~A}, 3 \mathrm{~B}, 3 \mathrm{C}$ and $3 \mathrm{D})$. The capsid protein VP1 is variable and confers distinct antigenic properties. Based on VP1 gene sequence, EV71 can be divided into genotype A, B, and C [6]. Genogroups B and $C$ can be further divided into 5 additional subgenogroups, designated B1-B5 and $\mathrm{C} 1-\mathrm{C} 5$, respectively [4,7]. The predominant genotypes currently circulating are $\mathrm{C} 1, \mathrm{C} 4, \mathrm{C} 5$ and $\mathrm{B} 5$, and different genotypes of EV71 stains may co-circulate in the same areas. Additionally, recombination and positive selection contribute to the antigenic diversity of EV71, and intra- or inter-genotypic recombinant EV71 strains have been reported in large outbreaks in different countries $[8,9]$.

C Biomed Central

(c) 2011 Han et al; licensee BioMed Central Ltd. This is an Open Access article distributed under the terms of the Creative Commons Attribution License (http://creativecommons.org/licenses/by/2.0), which permits unrestricted use, distribution, and reproduction in any medium, provided the original work is properly cited. 
There is currently no specific antiviral therapy to cure and no vaccine to prevent severe EV71 infection, due in part to the lack of understanding of viral pathogenesis. Actually, the clinical manifestations of EV71 infections varied. Most EV71 infections are asymptomatic or limited to mild HFMD and herpangina. However, EV71 is a highly neurotropic virus that can cause severe neurological diseases and complication, such as aseptic meningitis, brainstem encephalitis, acute flaccid paralysis and neurogenic pulmonary edema, which has been reviewed previously [10]. The pathogenesis of severe EV71 infection remains somewhat unclear. Radiologic and pathologic evidences indicated brainstem as the major target of EV71 infection [11]. Study in mice also demonstrated that retrograde axonal transport in neuron cells might be the major transmission route of EV71 [12]. Laboratory and clinical data demonstrated that inflammatory and immune responses also contribute to the pathogenesis of EV71 related severe diseases [13].

Antibody-dependent enhancement (ADE) of virus infection is a phenomenon in which preexisting subneutralizing antibodies enhance virus entry and replication. This phenomenon was first described by Hawkes in 1964 [14], and then ADE infection has been identified for many important viruses, including dengue virus, respiratory syncytial virus, human immunodeficiency virus, and Ebola virus. Several reports indicated that ADE was observed for members of the Picornaviridae family including foot-and-mouth disease virus [15], poliovirus [16], and coxsackievirus B $[17,18]$. Just during our submission, a group from Taiwan successfully demonstrated the ADE infection of EV71 in THP-1 cells for the first time [19].

Seroepidemiological survey has demonstrated that the high morbidity and mortality occur in 6-11 months old infants [20], which is correlated with the coincident decline in maternal antibodies [21]. The association of pre-existing antibodies with the increased severity of disease deserves further concerns and investigation. Here in this study, the possible role of sub-neutralizing antibodies during EV71 infection in vitro and in vivo was observed, and the association of ADE with disease development was analyzed in a secondary EV71 infection model.

\section{Results}

Previously, we have shown that commercial human IVIG preparations manufactured from Chinese plasma donors contain high titer neutralizing antibodies against EV71 [22]. Here to observe the possible ADE effects of EV71 infection, varying concentrations of IVIG preparations were used to incubate with EV71 to form antibody-virus complex before infecting THP-1 cells. The results of plaque assay showed that stock solution of IVIG can completely block EV71 infection in THP-1 cells, and PBS control has no effects on viral yield as expected (Figure 1A). Further dilutions of IVIG decreased the ability of EV71 neutralization, while at the $10^{-3}$ dilution of IVIG $(50 \mu \mathrm{g} / \mathrm{ml})$, a significant increase in virus titer was observed. The curves of viral yield from each dilutions coincided well with the ADE phenomenon (Figure 1B). Furthermore, real-time RT-PCR results also demonstrated that high concentration of IVIG ( $10^{-1}$ dilution) prevent EV71 infection, while lower concentration of IVIG $\left(10^{-3}\right.$ dilution) enhanced EV71 infection (data not shown). These experiments demonstrated lower concentration of neutralizing antibodies against EV71 can enhance EV71 infection in a monocytic cell line.

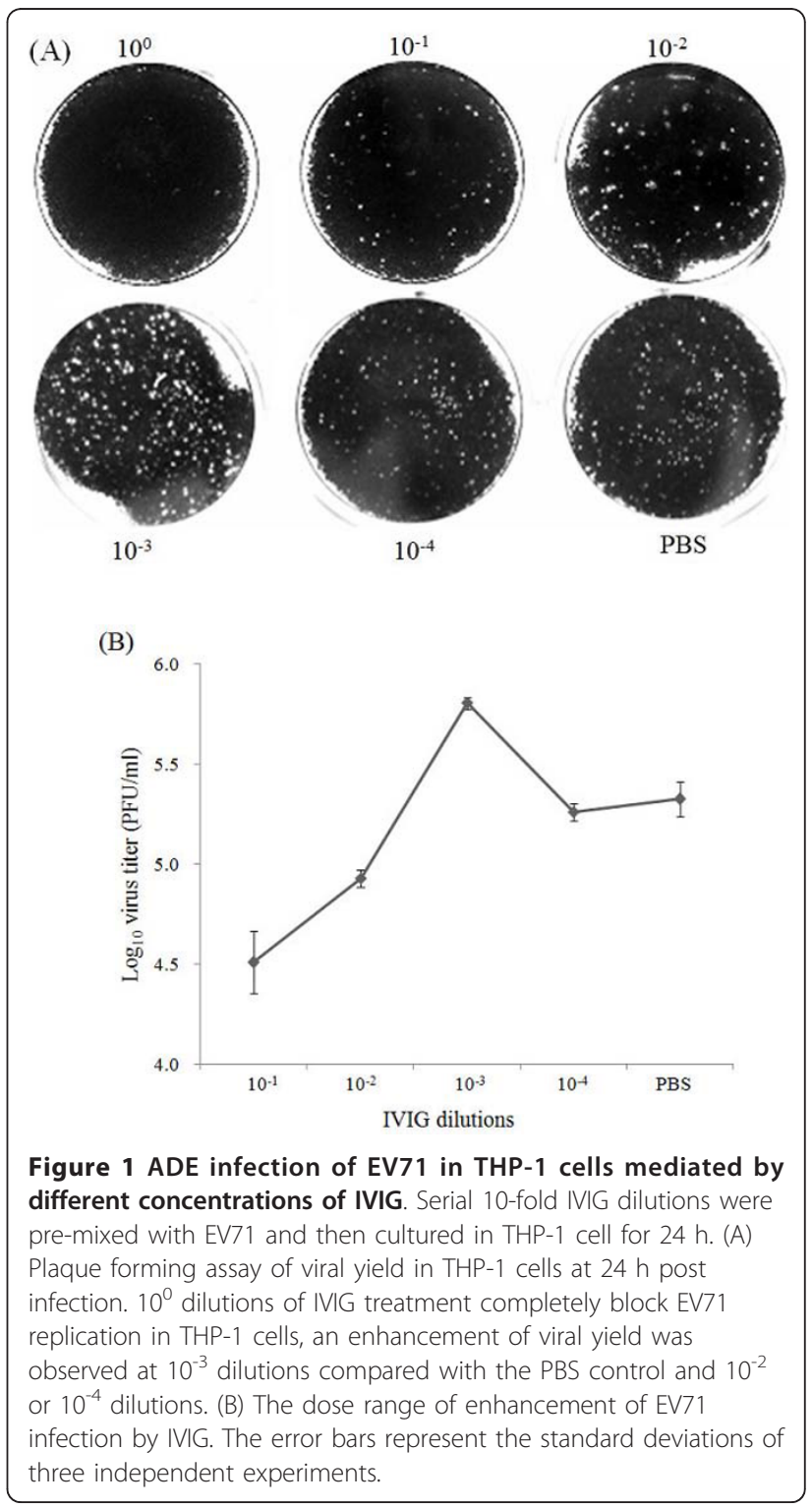


Next, to characterize the role of IVIG on EV71 infection in vivo, EV71 was pre-mixed with different concentration of IVIG or PBS were intraperitoneally injected into 1 -day-old mice $(\mathrm{n}=11)$, respectively. The survival curves (Figure 2A) showed that in the PBS control group, 7 of 11 (64\%) mice infected with EV71 infection survived. High concentration of IVIG $\left(10^{0}\right.$ and $10^{-1}$ dilutions) provided full protection against lethal EV71 challenge, demonstrating the protective role of neutralizing antibodies. Further dilution of IVIG $\left(10^{-3}\right.$ dilution) led to a similar effect as the PBS control, indicating no effective neutralizing antibodies at this concentration. Significantly, $10^{-2}$ dilution of IVIG $(500 \mu \mathrm{g} / \mathrm{ml})$ increased the mortality of EV71

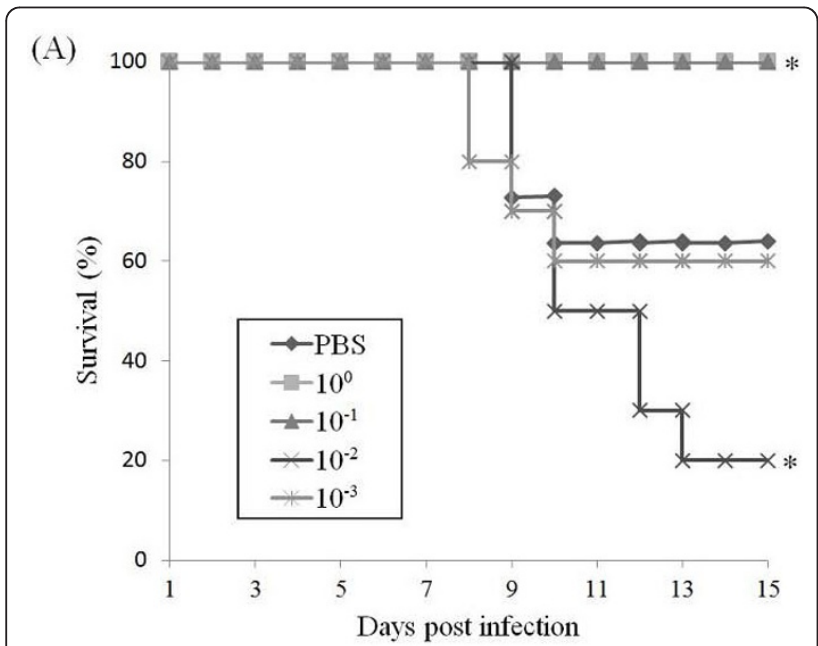

(B)

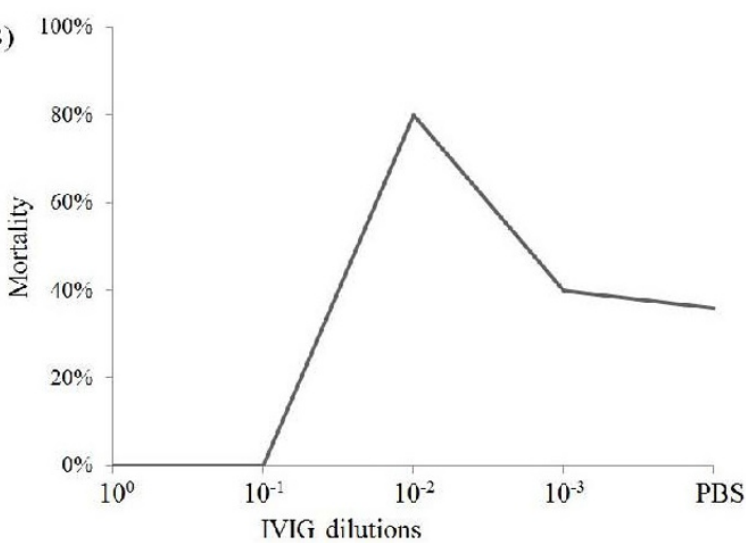

Figure 2 Lower concentration of IVIG enhanced the mortality of EV71-infected mice. Groups of 1-day-old mice $(n=11)$ were injected with $1 \mathrm{LD}_{50}$ of AH08/06 strain pre-mixed with varying concentration of IVIG. The mortality was further monitored for 2 weeks. (A) Kaplan-Meier survival curves were analyzed by the log-rank test and compared to curves of the PBS controls.

Significant differences are indicated by asterisks. (B) Mortality curves of mice treated with different IVIG dilutions. $10^{-2}$ dilution of IVIG resulted in $80 \%$ death in EV71-infected mice. infection, resulting in $80 \%$ deaths in EV71-infected mice. These findings demonstrated that high concentration of IVIG $\left(10^{0}\right.$ and $10^{-1}$ dilution) can prevent deaths caused by EV71 infection in mice, while the pre-incubation of EV71 with sub-neutralization concentration of IVIG $\left(10^{-2}\right.$ dilution) increased the mortality of EV71 infection in mice, thus ADE phenomenon occurred in vivo (Figure 2B).

Secondary infection model of dengue virus had been well established for ADE research in mice [23] and Rhesus monkeys [24]. Here, we manage to develop a secondary infection model of EV71 in which 1-day-old mice were first infected with an avirulent EV71 strain HN08/08 and subsequently infected with a virulent EV71 strain AH08/06 14 days after the primary infection. After the primary infection with $\mathrm{HN} 08 / 08$, all the infected mice survived, and no neurological symptoms developed. Serum examination showed that no neutralizing antibodies $(<1: 8)$ were detected in all of the infected mice, that means only sub-neutralizing antibody was induced. While after the secondary infection with the virulent strain AH08/06, groups of mice that primary injected with HN08/08 developed typical neurological manifestation, including movement disorientation, hind limb paralysis and opisthotonus (Figure 3). The survival curves (Figure 4) showed that $44 \%$ (4 of 9) of the mice that primary injected with PBS survived after the secondary infection with AH08/06. While primary injected with $10^{5}$ and $10^{6} \mathrm{PFU}$ of HN08/08 significantly increased the mortality to $100 \%$, and all of the mice died within 9-14 days after the secondary infection. Additionally, primary injected with a higher dose $\left(10^{7}\right.$ PFU) of HN08/08 resulted in 50\% (5 of 10) deaths, conferring no significant difference with the PBS control group. Thus, previous infection with $10^{5}$ and $10^{6}$ PFU EV71 was shown to increase the mortality of sequential EV71 infection in mice. Together, these results strongly indicated that the preinfection induced sub-neutralizing antibodies might enhance EV71 infection, and might be associated with disease development.

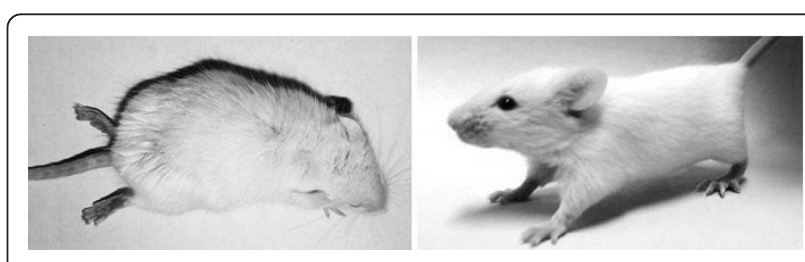

Figure $3 \mathrm{~A}$ representative picture of hind limb paralysis caused by the secondary infection of EV71 (10 days post the secondary infection). The mouse on the right-hand side is an agematched (23-day-old) control. 


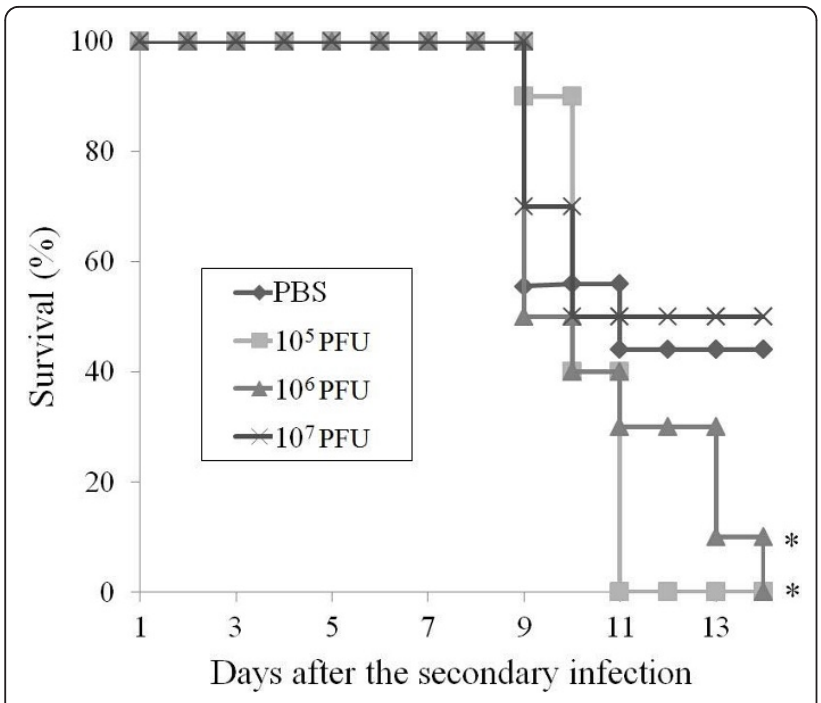

Figure 4 The secondary infection model of EV71. Groups of 1day-old mice were first injected with different doses $\left(10^{5}, 10^{6}\right.$, and $10^{7} \mathrm{PFU} /$ per mouse) of an avirulent EV71 strain (HN08/08) and then challenged with a virulent EV71 strain (AH08/06) 14 days later. The surviving curves after the secondary EV71 infection was analyzed by log-rank test and significant differences are indicated by asterisks. One representation of three independent experiments is shown.

\section{Discussion}

Our results provided evidence that pre-existing antibodies can enhance EV71 infection in vitro and in vivo. High concentration of IVIG can neutralize EV71, while further dilutions of IVIG led to an increase of viral replication and yield in THP-1 cells, and resulted in a higher mortality in mice. In the secondary EV71 infection model, primary infection with an avirulent EV71 strain result in a higher mortality of sequential EV71 infection in mice, indicating previous EV71 infection may be a potential risk factor for severe diseases during sequential EV71 infection. The present findings not only indicate ADE contribute to the pathogenesis of severe EV71 infection, but also raise practical issues about the development of vaccines and passive therapy with antibodies against EV71.

Mouse and cynomolgus macaque models have been established to study the pathogenesis and evaluate antivirals and vaccines [25]. Experimental infection with EV71 has been shown to cause death in neonatal mice in an age- and dose-dependent manner [26]. And 14day-old suckling mice are susceptible to virulent EV71 strain and have been used for vaccine evaluation [27]. The virulent strain AH08/06 and avirulent strain HN08/ 08 were both isolated in our laboratory and intraperitoneally injection with AH08/06 can result in neurological symptoms and deaths in different age of suckling mice [28]. EV71 antigen can be detected in the brain, and histopathological analysis of tissues from mice showed signs of infection (unpublished data). By using these strains, the secondary EV71 infection model were developed, and the results showed that preliminary exposure to an avirulent EV71 strain before secondary EV71 infection increased the risk of developing severe neurological complications and deaths. Multiple genotypes of EV71 strains co-circulate in in the same areas for a long time [10], and large outbreaks are probably associated with genotype replacement [8]. A recent report has shown that repeated EV71 infection is common during large outbreaks in China [29]. This is particularly important considering the fact that most primary EV71 infections are asymptomatic.

The target cells of EV71 in human tissues and organs have not been identified. Previous experiments showed that coxsackieviruses could replicate in lymphocytes and monocytes $[17,30]$. Human monocytic cell line THP-1 has Fc and complement receptor that is used for in vitro ADE assay in this study. The mechanism for ADE of EV71 infection is still unknown. Different mechanisms for ADE has been hypothesized, in which Fc receptor, complement receptor, $\beta 2$-microglobulin have been reported to play a role. Wang et al recently demonstrated that Fcy-receptor may participate in EV71induced ADE based on results from THP-1 cells [19]. Arita et al also reported high-affinity Fc receptor mediated enhancement of poliovirus infection [31]. Further, EV71 encodes 4 structural proteins (VP1-4), and the viral antigenic determinants associated with ADE of EV71 are also critical for future investigation. Recently, Chehadeh et al. [32] demonstrated that VP4 protein is the major target of enhancing antibodies in the CVB4 and CVB3 ADE model. By using monoclonal antibodies screening, the prM protein of dengue virus was recently identified as the critical ADE determinants [33]. We have produced a panel of EV71 mAbs and such efforts are currently underway. Additionally, ADE infection of non-enveloped virus requires binding of virus-antibody complexes both to Fc $\gamma$-receptor and to the specific viral receptor [34]. The role of PSGL-1 [35] and SCARB2 [36], two EV71 receptors, during ADE of EV71 infection deserves further research.

IVIG is a pharmaceutically preparation of human IgG that has immunoregulatory and anti-inflammatory properties. Clinically administration during EV71 outbreaks in Taiwan $[37,38]$ had achieved an improvement in clinical outcome. The Ministry of Health of China has recommended high dose (total $2 \mathrm{~g} / \mathrm{kg}$ in 2-5 days) of IVIG for treatment of severe EV71 infection. However, considering the fact that IVIG contains anti-EV71 antibodies [22], the potential risk of IVIG induced ADE of EV71 infection, especially the dose, must be carefully considered in future clinical application. The enhancing concentrations of IVIG may vary. Our experiments showed $50 \mu \mathrm{g} / \mathrm{ml}$ of IVIG enhanced EV71 infection in vitro, while $500 \mu \mathrm{g} / \mathrm{ml}$ in vivo. 
Wang et al showed that $0.5-1$ or $8-16 \mathrm{mg} / \mathrm{ml}$ of IVIG enhanced EV71 infection in THP-1 cells. The difference may results from the different sources of IVIG and the methodology applied $[19,22]$.

Given the public health significance of EV71, a wide range of experimental EV71 vaccine approaches have been studied, and neutralizing antibodies have been suggested as one of the most important factors in limiting the severity of infection. But considering the possible impact of $\mathrm{ADE}$, vaccines should be carefully designed to avoid the induction of known enhancing antibodies. Antibody responses induced by inactivated or subunit vaccines tend to be associated with severe disease by respiratory syncytial virus and retroviruses $[39,40]$. Induction of cellular immunity, rather than antibodies, may represent an alternative strategy for future EV71 vaccine development [41]. Live attenuated vaccine other than inactivated vaccine will be a good candidate.

Taken together, the present findings from laboratory and animal experiments demonstrate that the presence of sub-neutralizing antibodies would enhance EV71 infection, and primary EV71 infection might represent a risk factor of severe diseases during sequential EV71 infection. Controlled clinical trials are critically needed to confirm the correlation between disease severity and $\mathrm{ADE}$. Also, much effort is currently underway to determine the cellular and viral determinants of EV71induced ADE. The results of this and future studies thus contribute to a better understanding of the pathogenesis of EV71 infection, as well as an improved ability to evaluate vaccines and therapeutic antibodies.

\section{Materials and methods \\ Viruses and cells}

Human rhabdomyosarcoma (RD) cells were cultured with DMEM supplemented with $2 \%$ fetal bovine serum (FBS), $100 \mathrm{IU}$ of penicillin, and $100 \mu \mathrm{g}$ of streptomycin per $\mathrm{ml}$ at $37^{\circ} \mathrm{C}$ in the presence of $5 \% \mathrm{CO}_{2}$. Human monocytic cells (THP-1) were used for in vitro ADE assay and maintained in RPMI-1640 media at $37^{\circ} \mathrm{C}$ in $5 \% \mathrm{CO}_{2}$. EV71 strain AH08/06 was isolated from the throat swab sample of an HFMD case during an outbreak in 2008 in Anhui, China [39]. EV71 strain HN08/08 was isolated from the stool sample of an HFMD case during an outbreak in 2008 in Henan, China. All the viruses were propagated and titrated in RD cells and the stock was stored in aliquots at $-80^{\circ} \mathrm{C}$ in our laboratory. The titer of EV71 was expressed as $50 \%$ tissue culture infection dose $\left(\mathrm{TCID}_{50}\right)$, plaque-forming units (PFU) or $50 \%$ lethal dose $\left(\mathrm{LD}_{50}\right)$ according to the Reed-Muench method [42].

\section{Microneutralizing assay}

The titer of neutralizing antibodies against EV71 was determined in RD cells according to standard protocol
[43]. Briefly, $50 \mu \mathrm{L}$ of sample dilutions and $50 \mu \mathrm{L}$ of virus stock containing 100 TCID $_{50}$ EV71 were mixed and incubated onto the microtiter plates with RD cells at $37^{\circ} \mathrm{C}$ for 6 days. All the samples were tested at an initial dilution of $1: 8$, and cell and virus controls were run simultaneously. The neutralizing antibody titer was defined as the highest dilution of serum that could prevent the occurrence of cytopathic effect.

\section{Human Intravenous Immunoglobulin (IVIG) preparations} Human 5\% liquid IVIG preparations $(5 \mathrm{~g} / 100 \mathrm{ml}$, Tonrol Bio-Pharmaceutical) manufactured from Chinese plasma donors, consisting more than $99 \%$ of $\operatorname{IgG}$ and a very small quantities of IgA and IgM, were used as stock dilutions. The titer of neutralizing antibodies of IVIG was calculated to $1: 128$ by microneutralzing assay as previously described.

\section{ADE infection assay in vitro}

Stock IVIG preparation $\left(10^{\circ}\right.$ dilution) was 10 -fold serially diluted to $10^{-4}$ with PBS and each dilution was then incubated with EV71 suspensions at $37^{\circ} \mathrm{C}$ for $1 \mathrm{~h}$ to form virus-antibody complexes, respectively. The EV71-antibody complexes were then added to cultured THP-1 cells at a multiplicity of infection (MOI) of 1 and incubated for $1 \mathrm{~h}$ at $37^{\circ} \mathrm{C}$. Then, THP- 1 cells were washed for three times with PBS and then incubated with fresh RPMI-1640 media for another $24 \mathrm{~h}$. Finally, the infected cells and supernatants were harvested and the virus yield was determined by the plaque assays and real-time RT-PCR assays.

\section{Plaque forming assay}

Monolayer RD cells were cultured in 12-well plates and serial 10-fold dilutions of viral suspensions were added for adsorption for $1 \mathrm{~h}$. Then, the virus suspension was replaced with DMEM containing 2\% FBS and low melting point agarose. Followed by incubation for $72 \mathrm{~h}$, the cells were fixed with $10 \%$ formaldehyde and subsequently stained with $1 \%$ crystal violet solution. The titer of EV71 was calculated and expressed as plaque-forming units $(\mathrm{PFU}) / \mathrm{ml}$.

\section{Real-time RT-PCR assay}

Viral RNA in EV71-infected THP-1 cells was assayed by real-time RT-PCR as previously described [44]. Viral RNA was extracted by the QIAmp Viral RNA Mini kit (Qiagen) and one-step RT-PCR was performed by using the PrimeScript One-Step RT-PCR kit (Takara) according to the manufacturer's instructions in Roche LightCycler 2.0 systems.

\section{In vivo neutralization assay of EV71}

Stock IVIG preparation was 10 -fold serially diluted mixed with EV71 suspensions as previous described. 
Four groups of 1-day-old Kunming mice $(\mathrm{n}=11)$ were injected intraperitoneally with these EV71-IVIG or EV71-PBS mixtures, respectively. The mortality and neurological symptoms were monitored for 15 days.

\section{Secondary EV71 infection model}

We use two EV71 strains to establish the secondary EV71 infection model: a virulent strain AH08/06 which can result in death in 14-day-old suckling mice and an avirulent strain HN08/08. Briefly, groups of suckling mice of 1-day-old were primary injected subcutaneously with $50 \mu \mathrm{l}$ of different doses $\left(10^{5}, 10^{6}\right.$ and $10^{7} \mathrm{PFU}$, respectively) of HN08/08 or PBS. Then 14 days after the primary infection, all the mice were subsequently infected with $1 \mathrm{LD}_{50}(50 \mu \mathrm{l})$ of AH08/06 by intraperitoneally injection. Before the secondary infection, $100 \mu \mathrm{l}$ of blood was obtained via tail vein bleeding and processed for microneutralizing assay. The mortality and neurological symptoms were followed for another 14 days post the secondary infection. All the animal experiments were approved and performed according to the guideline of Animal Experiment Committee of State Key Laboratory of Pathogen and Biosecurity.

\section{Statistical analysis}

Kaplan-Meier survival curves were used to display mortality data, and log rank analyses were performed to determine statistical significance between different groups.

\section{List of Abbreviations}

ADE: Antibody dependent enhancement; EV71: Enterovirus 71; HFMD: Hand, foot and mouth disease; IVIG: Intravenous Immunoglobulin; MOI: Multiplicity of infection; PFU: plaque-forming units; $\mathrm{TCID}_{50}: 50 \%$ tissue culture infection dose.

\section{Acknowledgements}

We thank Prof. Qi-Bin Leng (Institute Pasteur of Shanghai, CAS) and Prof. Yuan Qian (Capital Institute of Pediatrics, Beijing) for helpful discussions. This work was supported by the Beijing Natural Science Foundation (No.7112108), the National Natural Science Foundation of China (No.81000721) and the Major Special Program of National Science and Technology of China (2008ZX10004-015 and 2009ZX10004-401).

\section{Authors' contributions}

JFH and RYC performed the experiments and drafted the manuscript. YQD, TJ and XT participated in cell culture and animal experiments. EDQ and CFQ designed the study, supervised the work and edited the final version of this manuscript. All authors read and approved the final manuscript.

\section{Competing interests}

The authors declare that they have no competing interests.

Received: 25 October 2010 Accepted: 8 March 2011

Published: 8 March 2011

\section{References}

1. Chan LG, Parashar UD, Lye MS, Ong FG, Zaki SR, Alexander JP, Ho KK, Han LL, Pallansch MA, Suleiman AB, Jegathesan M, Anderson LJ: Deaths of children during an outbreak of hand, foot, and mouth disease in sarawak, malaysia: clinical and pathological characteristics of the disease. For the Outbreak Study Group. Clin Infect Dis 2000, 31:678-683.

2. Ho M, Chen ER, Hsu KH, Twu SJ, Chen KT, Tsai SF, Wang JR, Shih SR: An epidemic of enterovirus 71 infection in Taiwan. Taiwan Enterovirus Epidemic Working Group. N Engl J Med 1999, 341:929-935.

3. Chan KP, Goh KT, Chong CY, Teo ES, Lau G, Ling AE: Epidemic hand, foot and mouth disease caused by human enterovirus 71 , Singapore. Emerg Infect Dis 2003, 9:78-85.

4. Tu PV, Thao NT, Perera D, Huu TK, Tien NT, Thuong TC, How OM, Cardosa MJ, McMinn PC: Epidemiologic and virologic investigation of hand, foot, and mouth disease, southern Vietnam, 2005. Emerg Infect Dis 2007, 13:1733-1741.

5. Yang F, Ren L, Xiong Z, Li J, Xiao Y, Zhao R, He Y, Bu G, Zhou S, Wang J, Qi J: Enterovirus 71 outbreak in the People's Republic of China in 2008. J Clin Microbiol 2009, 47:2351-2352.

6. Blomqvist S, Paananen A, Savolainen-Kopra C, Hovi T, Roivainen M: Eight years of experience with molecular identification of human enteroviruses. J Clin Microbiol 2008, 46:2410-2413.

7. Mizuta K, Abiko C, Murata T, Matsuzaki Y, Itagaki T, Sanjoh K, Sakamoto M, Hongo S, Murayama S, Hayasaka K: Frequent importation of enterovirus 71 from surrounding countries into the local community of Yamagata, Japan, between 1998 and 2003. J Clin Microbiol 2005, 43:6171-6175.

8. Huang SW, Hsu YW, Smith DJ, Kiang D, Tsai HP, Lin KH, Wang SM, Liu CC, Su IJ, Wang JR: Reemergence of enterovirus 71 in 2008 in taiwan: dynamics of genetic and antigenic evolution from 1998 to 2008. J Clin Microbiol 2009, 47:3653-3662.

9. Chen X, Zhang Q, Li J, Cao W, Zhang JX, Zhang L, Zhang W, Shao ZJ, Yan Y: Analysis of recombination and natural selection in human enterovirus 71. Virology 2010, 398:251-261.

10. Bek JEmily, McMinn CPeter: Recent advances in research on human enterovirus 71. Future Virology 2010, 5:453-468.

11. Weng KF, Chen LL, Huang PN, Shih SR: Neural pathogenesis of enterovirus 71 infection. Microbes Infect 2010, 12:505-510.

12. Chen CS, Yao YC, Lin SC, Lee YP, Wang YF, Wang JR, Liu CC, Lei HY, Yu CK: Retrograde axonal transport: a major transmission route of enterovirus 71 in mice. J Virol 2007, 81:8996-9003.

13. Wang SM, Lei HY, Huang KJ, Wu JM, Wang JR, Yu CK, Su IJ, Liu CC: Pathogenesis of enterovirus 71 brainstem encephalitis in pediatric patients: roles of cytokines and cellular immune activation in patients with pulmonary edema. J Infect Dis 2003, 188:564-570.

14. HAWKES RA: Enhancement of the infectivity of arboviruses by specific antisera produced in domestic fowls. Aust J Exp Biol Med Sci 1964, 42:465-482.

15. Baxt B, Mason PW: Foot-and-mouth disease virus undergoes restricted replication in macrophage cell cultures following Fc receptor-mediated adsorption. Virology 1995, 207:503-509.

16. Palmer P, Charley B, Rombaut B, Daëron M, Lebon P: Antibody-dependent induction of type I interferons by poliovirus in human mononuclear blood cells requires the type II fcgamma receptor (CD32). Virology 2000, 278:86-94.

17. Hober D, Chehadeh W, Bouzidi A, Wattré P: Antibody-dependent enhancement of coxsackievirus B4 infectivity of human peripheral blood mononuclear cells results in increased interferon-alpha synthesis. $J$ Infect Dis 2001, 184:1098-1108.

18. Girn J, Kavoosi M, Chantler J: Enhancement of coxsackievirus B3 infection by antibody to a different coxsackievirus strain. J Gen Virol 2002, 83:351-358.

19. Wang SM, Chen IC, Su LY, Huang KJ, Lei HY, Liu CC: Enterovirus 71 infection of monocytes with antibody-dependent enhancement. Clin Vaccine Immunol 2010, 17:1517-1523.

20. Lu CY, Lee CY, Kao CL, Shao WY, Lee PI, Twu SJ, Yeh CC, Lin SC, Shih WY, Wu SI, Huang LM: Incidence and case-fatality rates resulting from the 1998 enterovirus 71 outbreak in Taiwan. J Med Virol 2002, 67:217-223.

21. Luo ST, Chiang PS, Chao AS, Liou GY, Lin R, Lin TY, Lee MS: Enterovirus 71 maternal antibodies in infants, Taiwan. Emerg Infect Dis 2009, 15:581-584.

22. Cao R, Han J, Deng Y, Yu M, Qin E, Qin C: Presence of high-titer neutralizing antibodies against enterovirus 71 in intravenous immunoglobulin manufactured from Chinese donors. Clin Infect Dis 2010, 50:125-126.

23. Kyle JL, Balsitis SJ, Zhang L, Beatty PR, Harris E: Antibodies play a greater role than immune cells in heterologous protection against secondary dengue virus infection in a mouse model. Virology 2008, 380:296-303. 
24. Koraka P, Benton S, van Amerongen G, Stittelaar KJ, Osterhaus AD: Characterization of humoral and cellular immune responses in cynomolgus macaques upon primary and subsequent heterologous infections with dengue viruses. Microbes Infect 2007, 9:940-946.

25. Arita M, Nagata N, Iwata N, Ami Y, Suzaki Y, Mizuta K, Iwasaki T, Sata T, Wakita T, Shimizu $H$ : An attenuated strain of enterovirus 71 belonging to genotype a showed a broad spectrum of antigenicity with attenuated neurovirulence in cynomolgus monkeys. J Virol 2007, 81:9386-9395.

26. Yu CK, Chen CC, Chen CL, Wang JR, Liu CC, Yan JJ, Su IJ: Neutralizing antibody provided protection against enterovirus type 71 lethal challenge in neonatal mice. J Biomed Sci 2000, 7:523-528.

27. Ong KC, Devi S, Cardosa MJ, Wong KT: Formaldehyde-inactivated wholevirus vaccine protects a murine model of enterovirus 71 encephalomyelitis against disease. J Virol 2010, 84:661-665.

28. Han JF, Cao RY, Tian X, Yu M, Qin ED, Qin CF: Producing infectious enterovirus type 71 in a rapid strategy. Virol J 2010, 7:116

29. Yan L, Huang XX, Wang XF: Geographic epidemiological characteristics of repeated hand foot mouth disease infection in China. Chin Prev Med 2010, 11:548-550.

30. Vuorinen T, Vainionpää R, Heino J, Hyypiä T: Enterovirus receptors and virus replication in human leukocytes. J Gen Virol 1999, 80:921-927.

31. Arita M, Horie $H$, Arita M, Nomoto A: Interaction of poliovirus with its receptor affords a high level of infectivity to the virion in poliovirus infections mediated by the Fc receptor. J Virol 1999, 73:1066-1074.

32. Chehadeh W, Lobert PE, Sauter P, Goffard A, Lucas B, Weill J, Vantyghem MC, Alm G, Pigny P, Hober D: Viral protein VP4 is a target of human antibodies enhancing coxsackievirus B4 and B3-induced synthesis of alpha interferon. J Virol 2005, 79:13882-13891.

33. Dejnirattisai $W$, Jumnainsong A, Onsirisakul N, Fitton P, Vasanawathana $S$, Limpitikul W, Puttikhunt C, Edwards C, Duangchinda T, Supasa S, Chawansuntati K, Malasit P, Mongkolsapaya J, Screaton G: Cross-reacting antibodies enhance dengue virus infection in humans. Science 2010, 328:745-748.

34. Sauter $P$, Hober D: Mechanisms and results of the antibody-dependent enhancement of viral infections and role in the pathogenesis of coxsackievirus B-induced diseases. Microbes Infect 2009, 11:443-451.

35. Nishimura $Y$, Shimojima M, Tano Y, Miyamura T, Wakita T, Shimizu H: Human P-selectin glycoprotein ligand-1 is a functional receptor for enterovirus 71. Nat Med 2009, 15:794-797.

36. Yamayoshi S, Yamashita Y, Li J, Hanagata N, Minowa T, Takemura T, Koike S: Scavenger receptor B2 is a cellular receptor for enterovirus 71. Nat Med 2009, 15:798-801.

37. Wang SM, Lei HY, Huang MC, Su LY, Lin HC, Yu CK, Wang JL, Liu CC: Modulation of cytokine production by intravenous immunoglobulin in patients with enterovirus 71-associated brainstem encephalitis. J Clin Virol 2006, 37:47-52.

38. Wang SM, Ho TS, Shen CF, Liu CC: Enterovirus 71, one virus and many stories. Pediatr Neonatol 2008, 49:113-115.

39. Polack FP: Atypical measles and enhanced respiratory syncytial virus disease (ERD) made simple. Pediatr Res 2007, 62:111-115.

40. Takada A, Kawaoka Y: Antibody-dependent enhancement of viral infection: molecular mechanisms and in vivo implications. Rev Med Virol 2003, 13:387-398.

41. Chang LY, Hsiung CA, Lu CY, Lin TY, Huang FY, Lai YH, Chiang YP, Chiang BL, Lee CY, Huang LM: Status of cellular rather than humoral immunity is correlated with clinical outcome of enterovirus 71. Pediatr Res 2006, 60:466-471.

42. Reed $\sqcup$, Muench $\mathrm{H}$ : A simple method of estimating fifty per cent endpoints. Am J Hyg 1938, 27:493-497.

43. Chang LY, Tsao KC, Hsia SH, Shih SR, Huang CG, Chan WK, Hsu KH, Fang TY, Huang YC, Lin TY: Transmission and clinical features of enterovirus 71 infections in household contacts in Taiwan. JAMA 2004, 291:222-227.

44. Tan EL, Yong LL, Quak SH, Yeo WC, Chow VT, Poh CL: Rapid detection of enterovirus 71 by real-time TaqMan RT-PCR. J Clin Virol 2008, 42:203-206.

doi:10.1186/1743-422X-8-106

Cite this article as: Han et al:: Antibody dependent enhancement infection of Enterovirus 71 in vitro and in vivo. Virology Journal 2011 8:106.

\section{Submit your next manuscript to BioMed Central and take full advantage of:}

- Convenient online submission

- Thorough peer review

- No space constraints or color figure charges

- Immediate publication on acceptance

- Inclusion in PubMed, CAS, Scopus and Google Scholar

- Research which is freely available for redistribution

Submit your manuscript at www.biomedcentral.com/submit
Biomed Central 